\title{
Impact of early-onset seizures on grading and outcome in patients with subarachnoid hemorrhage
}

\author{
Christian Fung, MD, ${ }^{1}$ Mathias Balmer, MD, ${ }^{1}$ Michael Murek, MD,, Werner J. Z’Graggen, MD,, ${ }^{1,2}$ \\ Janine Abu-Isa, MD, ${ }^{1}$ Christoph Ozdoba, MD, ${ }^{3}$ Matthias Haenggi, MD, ${ }^{4}$ \\ Stephan M. Jakob, MD, PhD, ${ }^{4}$ Andreas Raabe, MD, ${ }^{1}$ and Jürgen Beck, MD ${ }^{1}$
}

\begin{abstract}
${ }^{1}$ Department of Neurosurgery, ${ }^{2}$ Department of Neurology, ${ }^{3}$ Institute for Diagnostic and Interventional Neuroradiology, and ${ }^{4}$ Department of Intensive Care Medicine, University Hospital (Inselspital) and University of Bern, Switzerland
\end{abstract}

\begin{abstract}
OBJECT After subarachnoid hemorrhage (SAH), seizure occurs in up to $26 \%$ of patients. The impact of seizure on outcome has been studied, yet its impact on grading is unknown. The authors evaluated the impact of early-onset seizures (EOS) on grading of spontaneous SAH and on outcome.

METHODS This retrospective analysis included consecutive patients with SAH who were treated at the NeuroCenter, Inselspital, University Hospital Bern, Switzerland, between January 2005 and December 2010. Demographic data, clinical data, and reports of EOS were recorded. The EOS were defined as seizures occurring within 24 hours after ictus. Patients were graded according to the World Federation of Neurosurgical Societies (WFNS) scale pre- and postresuscitation and dichotomized into good (WFNS I-III) and poor (WFNS IV-V) grades. Outcome was assessed at 6 months by using the modified Rankin Scale (mRS); an mRS score of $0-3$ was considered a good outcome and an mRS score of 4-6 was considered a poor outcome.
\end{abstract}

RESULTS Forty-one of 425 patients with SAH had EOS. Twenty-seven of those 41 patients (65.9\%) had a poor WFNS grade. Twenty-eight (68.3\%) achieved a good outcome, $11(26.8 \%)$ had a poor outcome, and $2(4.9 \%)$ were lost to followup. Early-onset seizures were proven in 9 of 16 electroencephalograms. The EOS were associated with poor WFNS grade (OR 2.81, 97.5\% Cl 1.14-7.46; $p=0.03$ ) and good outcome (OR 4.01, 97.5\% Cl 1.63-10.53; $p=0.03$ ). Increasing age, hydrocephalus, intracerebral hemorrhage, and intraventricular hemorrhage were associated with poor WFNS grade, whereas only age, intracerebral hemorrhage $(p<0.001)$, and poor WFNS grade $(p<0.001)$ were associated with poor outcome.

CONCLUSIONS Patients with EOS were classified significantly more often in a poor grade initially, but then they significantly more often achieved a good outcome. The authors conclude that EOS can negatively influence grading. This might influence decision making for the care of patients with SAH, so grading of patients with EOS should be interpreted with caution.

http://thejns.org/doi/abs/10.3171/2014.10.JNS14163

KEY WORDS early-onset seizure; modified Rankin Scale; subarachnoid hemorrhage; World Federation of Neurosurgical Societies grade; vascular disorders

$\mathrm{O}$ $\mathrm{N}$ presentation at a neurosurgical-neurovascular center, patients suffering from aneurysmal subarachnoid hemorrhage (SAH) may exhibit a reduced level of consciousness due to initial bleeding, rebleeding, hydrocephalus, sedation, or seizure ${ }^{1,9,15,20,22}$ as well as other conditions. Subarachnoid hemorrhage causes seizures in up to $26 \%$ of patients, which occur most com- monly within the first 24 hours. ${ }^{3,9,20,23}$ Most seizures occur before hospital presentation. ${ }^{20}$ The severity of SAH, as graded on scales like the World Federation of Neurosurgical Societies (WFNS) scale, as well as intracerebral hemorrhage (ICH), localization of the aneurysm, and the amount of subarachnoid blood are important risk factors for the development of early seizures.,17 The presence and

ABBREVIATIONS AED = antiepileptic drug; EEG = electroencephalography; EOS = early-onset seizures; EVD = external ventricular drain; GCS = Glasgow Coma Scale; $\mathrm{ICH}=$ intracerebral hemorrhage; IQR = interquartile range; IVH = intraventricular hemorrhage; $m R S$ = modified Rankin Scale; SAH = subarachnoid hemorrhage; WFNS = World Federation of Neurosurgical Societies.

SUBMITTED January 20, 2014. ACCEPTED October 22, 2014.

INCLUDE WHEN CITING Published online December 5, 2014; DOI: 10.3171/2014.10.JNS14163.

DISCLOSURE The authors report no conflict of interest concerning the materials or methods used in this study or the findings specified in this paper. 
incidence of SAH-related seizures and nonconvulsive status epilepticus influences patients' outcomes. ${ }^{2,3,5,6,9,17,23}$ In addition, seizures, the postictal state, or status epilepticus may significantly influence the grading of a given patient.

For acute decision making and patient management, the severity of SAH as assessed by the WFNS scale is probably the most important single factor. ${ }^{21}$ This grading may be highly relevant in the acute phase, especially for the patients with poor grades, because important management decisions like withdrawal of care are made in this early period. Up to now, the possible implication of seizures for grading of patients has not been analyzed. This report aims to highlight whether and to what extent seizures influence the grading of patients and outcome after SAH. We hypothesize that early-onset seizures (EOS) negatively influence grading of patients with $\mathrm{SAH}$ without being associated with poor outcome.

\section{Methods}

We performed a retrospective analysis of consecutive patients with spontaneous SAH admitted to the Department of Neurosurgery, University Hospital Bern, Switzerland, between January 2005 and December 2010. The patient's WFNS score was assessed on admission and after neurological resuscitation. ${ }^{7}$ Neurological resuscitation included intubation and mechanical ventilation for airway protection or, if respiratory distress developed, placement of arterial and venous lines, a CSF diversion via an external ventricular drain (EVD) or lumbar drain in case of hydrocephalus, and initiation of antiepileptic drugs (AEDs) after reported seizure, with administration of parenteral fluids to maintain euvolemia and initiation of nimodipine on admission. ${ }^{8}$ In cases in which the patient's Glasgow Coma Scale (GCS) score could not be assessed due to continued sedation, the last GCS score before intubation was used. Patients were dichotomized into good-grade (WFNS I-III) and poor-grade (WFNS IV-V) groups.

A thorough chart review was performed and the GCS score as well as reports of seizures were noted at distinct time points $\left.{ }^{24}: 1\right)$ at first contact with medical personnel (e.g., family practitioner, emergency technician, or another hospital); 2) on admission to our neurosurgical unit; 3) after neurological resuscitation but before aneurysm treatment; and 4) after securing the aneurysm. Seizures were defined as repetitive rhythmic jerking, with or without preceding tonic spasms, whether focal or generalized in nature, with or without loss of consciousness as convincingly described by a family practitioner, nonmedical witness, emergency staff, or physicians. ${ }^{2,17,20}$ Early-onset seizures were defined as those occurring within 24 hours after onset of headache. ${ }^{2}$ Because we were interested in the effect of seizure on grading of SAH, we analyzed seizures that took place from ictus until evaluation by a neurosurgeon, and after neurological resuscitation but within 24 hours after onset of headache. ${ }^{11,16}$ During data assessment, special attention was paid to avoid confusing EOS with posturing. Imaging at admission was used to determine ICH, hydrocephalus, and intraventricular hemorrhage (IVH). The volume of ICH was estimated using the "ABC/2" method.$^{10}$ Hydrocephalus was considered to be present in patients who had ventricular dilation on admission imaging. For these patients, an external CSF or lumbar drain was inserted. Outcome was assessed according to the modified Rankin Scale (mRS) at 6 months after ictus, and was dichotomized into good (mRS score of 0-3) and poor (mRS score of 4-6) outcome. ${ }^{19}$

The primary end point was grading of SAH according to the WFNS score. The secondary end point was outcome at 6 months as assessed by the mRS. The study was approved by the local ethics committee (Kantonale Ethikkommission Bern).

\section{Statistical Analysis}

Variables were chosen that might interfere with grading and outcome of patients with SAH. Univariate and multivariate analyses were conducted to analyze the impact of age, sex, presence of hydrocephalus, volume of ICH, IVH, and EOS on grading of patients with SAH before and after neurological resuscitation according to the WFNS grade as dependent variable. In addition, the impact of these factors and WFNS grade was analyzed with respect to outcome at 6 months after ictus, where outcome was the dependent variable. Differences between groups in the univariate analysis were tested using the Welch 2-sample t-test and the Fisher exact test, as appropriate. Multivariate analysis was performed with a binary logistic regression model. Odds ratios and confidence intervals were calculated; $p$ values $<0.05$ were considered significant. The odds ratio for the 2 continuous variables age and ICH volume were calculated per 1-unit increment of the respective variable (1 patient year, $1 \mathrm{ml}$ hematoma volume). Statistical analysis was performed with "The R Project for Statistical Computing" (http://www.r-project.org).

\section{Results}

Of the 425 patients with SAH included in this study, 187 were initially graded WFNS I, 64 were Grade II, 10 were Grade III, 60 were Grade IV, and 104 were Grade $\mathrm{V}$. The cohort consisted of 280 female and 145 male patients (female to male ratio 1.9:1) with a median age of 56 years (interquartile range [IQR] 49-66 years). Complete data sets including outcome data were available for 359 of 425 patients; 66 patients (15.5\%) were lost to follow-up (52 patients with WFNS Grade I, 12 with WFNS Grade II, and 2 with WFNS Grade III). Seven (12.5\%) of 56 patients with seizure were lost to follow-up, 2 of whom presented with an EOS.

\section{Seizure Characteristics}

In total, 56 of 425 patients $(13.2 \%)$ were reported to have suffered a seizure between initial ictus and discharge from the neurosurgical department. Of these, 24 patients $(42.9 \%)$ presented with a seizure at initial ictus, $17(30.4 \%)$ on admission at the emergency department before resuscitation, 4 (7.1\%) after neurological resuscitation, and $11(19.6 \%)$ after treatment of the aneurysm. Clinical presentations of EOS were described as primary generalized tonic-clonic seizure $(\mathrm{n}=38)$, secondary generalized seizure $(\mathrm{n}=3)$, and partial complex seizure $(\mathrm{n}=1)$. In 3 patients seizures were not further specified. Seizures were 
associated with urinary $(\mathrm{n}=11)$ and fecal $(\mathrm{n}=2)$ incontinence and tongue biting $(n=6)$. Of the 425 patients, 8 presented with posturing, and none of these had EOS.

Of the 41 patients who presented with EOS before neurological resuscitation, 24 were intubated at admission and 15 of these intubated patients received a specific AED treatment other than sedative medication. Seventeen patients were not intubated at admission, of whom 11 received AED treatment. The choice of AED treatment depended on the comorbidities and the type of seizures. In patients with status epilepticus the first choice was valproic acid, whereas in patients with self-limiting seizures, levetiracetam was the first choice. Depending on the clinical course, presence of additional seizures, and electroencephalography (EEG) results, continuation of AED treatment was decided on a case-by-case basis. In cases in which no additional seizures were observed, AEDs were generally discontinued after 14 days.

Of 41 patients in whom EOS occurred, an EEG study was performed in 16 . In these 16 cases, EEG showed epileptic activity in 9 patients (56\%) and 7 displayed nonepileptogenic EEG results. None of the EEG recordings was performed within the first 24 hours after ictus.

\section{Grading of Patients With SAH}

For the primary analysis we assessed 39 patients with EOS before neurological resuscitation. Three patients were graded WFNS I, 7 were Grade II, 2 were Grade III, 10 were Grade IV, and 17 were Grade V. Two patients with EOS were lost to follow-up. Outcome was good in 28 and poor in 11 cases (Table 1). Early-onset seizure was associated with a poor WFNS grade in both univariate (OR 3.0, 97.5\% CI 1.41-6.74; $\mathrm{p}=0.002$ ) and multivariate analyses (OR 2.81, 97.5\% CI 1.14-7.46; $\mathrm{p}=0.03$ ). Besides EOS, known risk factors like age, hydrocephalus, ICH, and IVH were associated with poor-grade SAH (Table 2).

After neurological resuscitation, 31 patients with EOS (75.6\%) had an EVD placed due to hydrocephalus. After placement of an EVD, 13 patients (41.9\%) showed an improvement in post- versus preresuscitation GCS (median

TABLE 1. Absolute numbers of patients with EOS for good and poor WFNS grade and dichotomized outcome*

\begin{tabular}{cccccc}
\hline \multirow{2}{*}{ WFNS Grade } & No. & $\%$ & & No. & $\%$ \\
\cline { 2 - 3 } \cline { 5 - 6 } Preresuscitation & & & & \\
\hline EOS & 28 of 41 & 68.3 & & 11 of 41 & 26.8 \\
\hline Good grade & 12 of 39 & 30.8 & & 0 & \\
\hline Poor grade & 16 of 39 & 41.0 & & 11 of 39 & 28.2 \\
\hline Postresuscitation & & & & \\
\hline EOS & 31 of 45 & 68.9 & & 12 of 45 & 26.7 \\
\hline Good grade & 15 of 43 & 34.9 & & 1 of 43 & 2.3 \\
\hline Poor grade & 16 of 43 & 37.2 & & 11 of 43 & 25.6 \\
\hline
\end{tabular}

\footnotetext{
* Prior to resuscitation 41 patients with EOS were identified, of whom 2 were lost to follow-up. Therefore only 39 were included in the preresuscitation detailed analysis. After neurological resuscitation, 4 additional patients presented with EOS. At this time point a total of 45 patients with EOS had been identified. Because 2 patients were lost to follow-up, only 43 were included in the postresuscitation detailed analysis.
}

GCS improvement 4 points [IQR 2-7]). Eighteen patients $(58.1 \%)$ with EOS presented a lower or unchanged GCS score after EVD placement.

One hundred forty-three patients without seizure had a CSF diversion (37.2\%) with available GCS scores before and after CSF diversion. Comparison of GCS scores at admission and postresuscitation showed that 15 patients (10.5\%) improved (median GCS improvement of 2 points [IQR 1-4]), whereas 128 patients $(89.5 \%)$ had a lower or unchanged GCS score after resuscitation. In patients with EOS, GCS improvement after CSF diversion was significantly higher than in patients without EOS (OR 6.07, 95\% CI 2.27-16.37; $\mathrm{p}=0.0001$ ).

After neurological resuscitation, 4 patients presented with seizures. We repeated the complete statistical analysis for the data after neurological resuscitation. At this time point, after neurological resuscitation, EOS was no longer associated with poor WFNS grade, either in a univariate (OR 1.81, 97.5\% CI 0.9-3.74; $\mathrm{p}=0.1$ ) or in a multivariate analysis (OR 1.32, 97.5\% CI 0.57-3.20; $\mathrm{p}=0.52$ ) (Table 2).

Other known parameters associated with poor grades, like age, hydrocephalus, ICH, and IVH were associated with poor WFNS grade (Table 2).

\section{Outcome of Patients With SAH}

Outcome after 6 months for patients with good and poor WFNS grade and EOS are displayed in Table 1. Almost $70 \%$ of patients with EOS showed a favorable outcome as defined by an mRS score of $0-3$. According to the preresuscitation WFNS grading, EOS were not associated with good outcome in the univariate analysis (OR 1.43, 97.5\% CI 0.66-3.30; $\mathrm{p}=0.38$ ). However, the multivariate analysis of EOS showed a significant association (OR 4.01, 97.5\% CI 1.63-10.53; $\mathrm{p}=0.03$ ) with outcome (Table 3).

After neurological resuscitation the univariate analysis showed no association of EOS and good outcome (OR $1.46,97.5 \%$ CI $0.7-3.26 ; p=0.31$, whereas in the multivariate analysis EOS were associated with good outcome (OR 2.6, 97.5\% CI 1.11-6.48; $\mathrm{p}=0.03$ ) (Table 3). This was in contrast to patients without EOS. In this group the same statistical analysis was performed. Here, a poor WFNS grade was associated with poor outcome at 6 months (OR $0.11,97.5 \%$ CI $0.05-0.23 ; \mathrm{p}<0.0001)$ independently of timing of assessment, and pre- or postresuscitation.

\section{Discussion}

To our knowledge this is the first report to analyze the impact of EOS on the grading of SAH. Early-onset seizures were significantly associated with poor grades. However, these patients had a good outcome. The discrepancy between initial poor grades and good outcome is intriguing, especially because in patients without EOS a poor grade remains associated with a poor outcome. Our most obvious explanation is that EOS distort the clinical status of patients temporarily, mimicking a worse clinical status and therefore a poorer WFNS grade. The clinical status reflected by the WFNS grade is one of the best predictors for clinical outcome. Our interpretation of the current data is that EOS are not the cause of good outcome in these patients; instead, EOS may contribute to a worse WFNS 
TABLE 2. Univariate and multivariate analyses with WFNS IV and V as outcome and dependent variable

\begin{tabular}{|c|c|c|c|c|c|c|}
\hline \multicolumn{7}{|c|}{ Preresuscitation: univariate analysis } \\
\hline Variable & Good Grade & Poor Grade & OR & $\mathrm{Cl} 2.5 \%$ & CI $97.5 \%$ & $\mathrm{p}$ Value \\
\hline Age $^{*}$ & 55 & 61 & & & & $<0.001$ \\
\hline Male sex & 62 & 50 & 0.94 & 0.59 & 1.51 & 0.82 \\
\hline Hydrocephalus & 88 & 150 & 12.93 & 6.87 & 25.98 & $<0.001$ \\
\hline EOS & 12 & 27 & 3.00 & 1.41 & 6.74 & 0.002 \\
\hline $\mathrm{ICH}^{*}$ & 2 & 12 & & & & $<0.001$ \\
\hline $\mathrm{IVH}$ & 76 & 141 & 9.53 & 5.53 & 16.99 & $<0.001$ \\
\hline \multicolumn{7}{|c|}{ Preresuscitation: multivariate analysis } \\
\hline Variable & Beta & OR† & $\mathrm{Cl} 2.5 \%$ & $\mathrm{Cl} 97.5 \%$ & Wald z-Score & $p$ Value \\
\hline $\mathrm{Age}^{*}$ & 0.04 & 1.04 & 1.01 & 1.06 & 2.9 & $<0.004$ \\
\hline Male sex & 0.28 & 1.32 & 0.72 & 2.47 & 0.88 & 0.376 \\
\hline Hydrocephalus & 2.15 & 8.55 & 4.22 & 18.78 & 5.68 & $<0.001$ \\
\hline EOS & 1.03 & 2.81 & 1.14 & 7.46 & 2.17 & 0.03 \\
\hline $\mathrm{ICH}^{*}$ & 0.06 & 1.06 & 1.04 & 1.10 & 4.13 & $<0.001$ \\
\hline $\mathrm{IVH}$ & 1.68 & 5.39 & 2.91 & 10.29 & 5.25 & $<0.001$ \\
\hline \multicolumn{7}{|c|}{ Postresuscitation: univariate analysis } \\
\hline Variable & Good Grade & Poor Grade & OR & $\mathrm{Cl} 2.5 \%$ & $\mathrm{Cl} 97.5 \%$ & $p$ Value \\
\hline $\mathrm{Age}^{*}$ & 54 & 61 & & & & $<0.001$ \\
\hline Male sex & 58 & 54 & 0.90 & 0.56 & 1.44 & 0.73 \\
\hline Hydrocephalus & 73 & 149 & 7.17 & 4.3 & 12.22 & $<0.001$ \\
\hline EOS & 16 & 27 & 1.81 & 0.9 & 3.74 & 0.1 \\
\hline $\mathrm{ICH}^{*}$ & 1 & 12 & & & & $<0.001$ \\
\hline $\mathrm{IVH}$ & 68 & 148 & 7.74 & 4.65 & 13.18 & $<0.001$ \\
\hline \multicolumn{7}{|c|}{ Postresuscitation: multivariate analysis } \\
\hline Variable & Beta & OR† & $\mathrm{Cl} 2.5 \%$ & $\mathrm{Cl} 97.5 \%$ & Wald z-Score & $p$ Value \\
\hline Age $^{*}$ & 0.05 & 1.05 & 1.03 & 1.08 & 4.16 & $<0.001$ \\
\hline Male sex & 0.23 & 1.26 & 0.68 & 2.36 & 0.74 & 0.46 \\
\hline Hydrocephalus & 2.05 & 7.73 & 4.09 & 15.33 & 6.1 & $<0.001$ \\
\hline EOS & 0.28 & 1.32 & 0.57 & 3.20 & 0.64 & 0.52 \\
\hline $\mathrm{ICH}^{*}$ & 0.10 & 1.10 & 1.06 & 1.16 & 4.39 & $<0.001$ \\
\hline IVH & 1.56 & 4.75 & 2.64 & 8.76 & 5.11 & $<0.001$ \\
\hline
\end{tabular}

* Expressed as mean values.

$\dagger$ In the multivariate analysis the odds ratios are given for increments of 1 patient year and $1 \mathrm{ml}$.

grade as compared with a similar patient without EOS. Thus, the presence of EOS conceals the more positive potential outcomes of such patients. This is displayed in our data by the fact that EOS are associated with poor WFNS grade only in the preresuscitation grading. Postresuscitation patients with EOS showed a clinical improvement, as evidenced by the lack of an association between EOS and poor WFNS grade. This clinical improvement postresuscitation, which is accompanied by a better WFNS grade, most likely explains the good outcome of patients with EOS after 6 months.

In our study cohort, $13.2 \%$ of patients presented with a seizure between initial ictus and discharge from the neurosurgical unit, which is consistent with previous reports. ${ }^{3,4,11,13,20}$ Of these, $73.2 \%$ suffered their seizure in the early phase, including the prehospitalization period up to neurological resuscitation. The impact of EOS on outcome has been previously studied. ${ }^{2,9,11,17,20}$ Some authors state that EOS are not associated with poor outcome,,${ }^{9,20}$ whereas Lin et al. say that EOS are associated with a persistent neurological deficit. ${ }^{11}$ On the other hand, Pinto et al. ${ }^{17}$ and Butzkueven et al. ${ }^{2}$ show a significant association with EOS and poor outcome, although in their studies outcome assessment was done on discharge and at 6 weeks after ictus, respectively. Due to the capacity for clinical improvement after $\mathrm{SAH}$, these time points for outcome assessment seem too early to draw definitive results.

\section{Seizures and Timing of Grading in Patients With SAH}

The current expert opinion is that postresuscitation neurological status is the best predictor of outcome in patients with SAH. ${ }^{8,14}$ This notion is corroborated by our data. Up to now, hydrocephalus has been thought to be the main confounder interfering with grading in patients with SAH. Another explanation suggested by our data is that EOS 
TABLE 3. Univariate and multivariate analyses with good outcome (mRS $0-3$ ) as outcome and dependent variable

\begin{tabular}{|c|c|c|c|c|c|c|}
\hline \multicolumn{7}{|c|}{ Preresuscitation: univariate analysis } \\
\hline Variable & $\mathrm{mRS} 4-6$ & mRS 0-3 & OR & $\mathrm{Cl} 2.5 \%$ & Cl $97.5 \%$ & p Value \\
\hline $\mathrm{Age}^{*}$ & 62 & 55 & & & & $<0.001$ \\
\hline Male sex & 32 & 80 & 1.53 & 0.92 & 2.58 & 0.95 \\
\hline Hydrocephalus & 110 & 128 & 0.18 & 0.09 & 0.33 & $<0.001$ \\
\hline EOS & 11 & 28 & 1.43 & 0.66 & 3.30 & 0.38 \\
\hline $\mathrm{ICH}^{*}$ & 15 & 2 & & & & $<0.001$ \\
\hline IVH & 103 & 114 & 0.05 & 0.03 & 0.09 & $<0.001$ \\
\hline WFNS IV \& V & 109 & 55 & 0.05 & 0.03 & 0.09 & $<0.001$ \\
\hline \multicolumn{7}{|c|}{ Preresuscitation: multivariate analysis } \\
\hline Variable & Beta & OR† & $\mathrm{Cl} 2.5 \%$ & Cl $97.5 \%$ & Wald z-Score & $p$ Value \\
\hline Age $^{*}$ & -0.03 & 0.97 & 0.95 & 1.00 & -2.31 & 0.02 \\
\hline Male sex & 0.63 & 1.88 & 0.98 & 3.68 & 1.87 & 0.06 \\
\hline Hydrocephalus & -0.49 & 0.61 & 0.26 & 1.42 & -1.14 & 0.25 \\
\hline EOS & 1.39 & 4.01 & 1.63 & 10.53 & 2.95 & 0.03 \\
\hline $\mathrm{ICH}^{*}$ & -0.04 & 0.96 & 0.94 & 0.98 & -3.39 & $<0.001$ \\
\hline IVH & -0.13 & 0.88 & 0.42 & 1.87 & -0.35 & 0.728 \\
\hline WFNS IV \& V & -2.70 & 0.07 & 0.03 & 0.14 & -7.18 & $<0.001$ \\
\hline \multicolumn{7}{|c|}{ Postresuscitation: univariate analysis } \\
\hline Variable & mRS 4-6 & mRS 0-3 & OR & $\mathrm{Cl} 2.5 \%$ & Cl $97.5 \%$ & $p$ Value \\
\hline $\mathrm{Age}^{*}$ & 62 & 55 & & & & $<0.001$ \\
\hline Male sex & 32 & 80 & 1.54 & 0.93 & 2.60 & 0.09 \\
\hline Hydrocephalus & 94 & 128 & 0.42 & 0.25 & 0.69 & $<0.001$ \\
\hline EOS & 12 & 31 & 1.46 & 0.70 & 3.26 & 0.31 \\
\hline $\mathrm{ICH}^{*}$ & 15 & 2 & & & & $<0.001$ \\
\hline $\mathrm{IVH}$ & 103 & 113 & 0.21 & 0.12 & 0.37 & $<0.001$ \\
\hline WFNS IV \& V & 108 & 71 & 0.07 & 0.04 & 0.13 & $<0.001$ \\
\hline \multicolumn{7}{|c|}{ Postresuscitation: multivariate analysis } \\
\hline Variable & Beta & OR† & $\mathrm{Cl} 2.5 \%$ & Cl $97.5 \%$ & Wald z-Score & $p$ Value \\
\hline $\mathrm{Age}^{*}$ & -0.03 & 0.97 & 0.95 & 0.99 & -2.35 & 0.02 \\
\hline Male sex & 0.49 & 1.62 & 0.88 & 3.04 & 1.55 & 0.12 \\
\hline Hydrocephalus & 0.07 & 1.07 & 0.53 & 2.21 & 0.19 & 0.85 \\
\hline EOS & 0.95 & 2.60 & 1.11 & 6.48 & 2.13 & 0.03 \\
\hline $\mathrm{ICH}^{*}$ & -0.03 & 0.97 & 0.94 & 0.98 & -3.39 & $<0.001$ \\
\hline IVH & -0.68 & 0.51 & 0.26 & 0.98 & -2.03 & 0.04 \\
\hline WFNS IV \& V & -2.07 & 0.13 & 0.06 & 0.25 & -5.72 & $<0.001$ \\
\hline
\end{tabular}

* Expressed as mean values.

$\dagger$ In the multivariate analysis the odds ratios are given for increments of 1 patient year and $1 \mathrm{ml}$.

may obscure grading in the initial phase. After neurological resuscitation there is no longer a statistical association between EOS and a poor grade. The GCS grades of patients with EOS significantly improved after neurological resuscitation. Clinical improvement of patients with EOS after neurological resuscitation can be attributed to the following circumstances: 1) correction of raised intracerebral pressure; 2) initiation of anticonvulsive treatment (propofol, benzodiazepines, AEDs); and 3) spontaneous improvement of patients due to the elapsed time between seizure and neurological resuscitation.

Confusing EOS with posturing seems unlikely to us. We specifically paid attention to this condition and identi- fied 8 patients in our cohort with posturing. None of these patients had EOS and all of them had a poor outcome. We know from the literature that patients who show posturing rarely improve and do not have a good outcome. ${ }^{18,25}$ In contrast, the EOS group showed good outcome at 6 months and better clinical improvement after neurological resuscitation.

Early-onset seizures occurred in $10.6 \%$ of our study cohort, regardless of WFNS grade, and it occurred in 41 of $164(25 \%)$ of patients with poor-grade SAH, compared with the published rates of hydrocephalus in SAH of up to $24 \% .^{12,15,22}$ Early-onset seizures might be an underestimated factor that interferes with WFNS grading. Hence, 
our data support the current opinion that grading of patients with SAH should be performed after neurological resuscitation.

The major limitations of this study are the retrospective design and single-center setting. In addition, differentiation between seizures, posturing, or a convulsive syncope can be difficult and these conditions might have been confused. Therefore, misdiagnosis cannot be excluded and patients without EOS might have been included in the study cohort. Also, we did not routinely perform EEG studies in patients with suspected seizure.

\section{Conclusions}

On the basis of our results we conclude that EOS may contribute substantially to improper grading of patients with SAH. The results support the current opinion that postresuscitation clinical status should be used for grading of SAH.

\section{References}

1. Bederson JB, Connolly ES Jr, Batjer HH, Dacey RG, Dion JE, Diringer MN, et al: Guidelines for the management of aneurysmal subarachnoid hemorrhage: a statement for healthcare professionals from a special writing group of the Stroke Council, American Heart Association. Stroke 40:994-1025, 2009 (Erratum in Stroke 40:e518, 2009)

2. Butzkueven H, Evans AH, Pitman A, Leopold C, Jolley DJ, Kaye AH, et al: Onset seizures independently predict poor outcome after subarachnoid hemorrhage. Neurology 55:1315-1320, 2000

3. Choi KS, Chun HJ, Yi HJ, Ko Y, Kim YS, Kim JM: Seizures and epilepsy following aneurysmal subarachnoid hemorrhage: incidence and risk factors. J Korean Neurosurg Soc 46:93-98, 2009

4. Claassen J, Mayer SA, Hirsch LJ: Continuous EEG monitoring in patients with subarachnoid hemorrhage. J Clin Neurophysiol 22:92-98, 2005

5. Claassen J, Peery S, Kreiter KT, Hirsch LJ, Du EY, Connolly ES, et al: Predictors and clinical impact of epilepsy after subarachnoid hemorrhage. Neurology 60:208-214, 2003

6. Dennis LJ, Claassen J, Hirsch LJ, Emerson RG, Connolly ES, Mayer SA: Nonconvulsive status epilepticus after subarachnoid hemorrhage. Neurosurgery 51:1136-1144, 2002

7. Drake CG, Hunt WE, Sano K, Kassell N, Teasdale G, Pertuiset B, et al: Report of World Federation of Neurological Surgeons Committee on a Universal Subarachnoid Hemorrhage Grading Scale. J Neurosurg 68:985-986, 1988 (Letter)

8. Giraldo EA, Mandrekar JN, Rubin MN, Dupont SA, Zhang Y, Lanzino G, et al: Timing of clinical grade assessment and poor outcome in patients with aneurysmal subarachnoid hemorrhage. J Neurosurg 117:15-19, 2012

9. Hart RG, Byer JA, Slaughter JR, Hewett JE, Easton JD: Occurrence and implications of seizures in subarachnoid hemorrhage due to ruptured intracranial aneurysms. Neurosurgery 8:417-421, 1981

10. Kothari RU, Brott T, Broderick JP, Barsan WG, Sauerbeck LR, Zuccarello M, et al: The ABCs of measuring intracerebral hemorrhage volumes. Stroke 27:1304-1305, 1996

11. Lin CL, Dumont AS, Lieu AS, Yen CP, Hwang SL, Kwan $\mathrm{AL}$, et al: Characterization of perioperative seizures and epilepsy following aneurysmal subarachnoid hemorrhage. J Neurosurg 99:978-985, 2003
12. Lin CL, Kwan AL, Howng SL: Acute hydrocephalus and chronic hydrocephalus with the need of postoperative shunting after aneurysmal subarachnoid hemorrhage. Kaohsiung J Med Sci 15:137-145, 1999

13. Lin YJ, Chang WN, Chang HW, Ho JT, Lee TC, Wang HC, et al: Risk factors and outcome of seizures after spontaneous aneurysmal subarachnoid hemorrhage. Eur J Neurol 15:451-457, 2008

14. Macdonald RL: Editorial. Outcome after aneurysmal subarachnoid hemorrhage. J Neurosurg 117:12-14, 2012

15. Mehta V, Holness RO, Connolly K, Walling S, Hall R: Acute hydrocephalus following aneurysmal subarachnoid hemorrhage. Can J Neurol Sci 23:40-45, 1996

16. Molyneux AJ, Kerr RS, Yu LM, Clarke M, Sneade M, Yarnold JA, et al: International Subarachnoid Aneurysm Trial (ISAT) of neurosurgical clipping versus endovascular coiling in 2143 patients with ruptured intracranial aneurysms: a randomised comparison of effects on survival, dependency, seizures, rebleeding, subgroups, and aneurysm occlusion. Lancet 366:809-817, 2005

17. Pinto AN, Canhao P, Ferro JM: Seizures at the onset of subarachnoid haemorrhage. J Neurol 243:161-164, 1996

18. Quigley MR, Salary M: Defining survivorship after highgrade aneurysmal subarachnoid hemorrhage. Surg Neurol 69:261-265, 2008

19. Rankin J: Cerebral vascular accidents in patients over the age of 60. II. Prognosis. Scott Med J 2:200-215, 1957

20. Rhoney DH, Tipps LB, Murry KR, Basham MC, Michael DB, Coplin WM: Anticonvulsant prophylaxis and timing of seizures after aneurysmal subarachnoid hemorrhage. Neurology 55:258-265, 2000

21. Rosen DS, Macdonald RL: Subarachnoid hemorrhage grading scales: a systematic review. Neurocrit Care 2:110-118, 2005

22. Suarez-Rivera O: Acute hydrocephalus after subarachnoid hemorrhage. Surg Neurol 49:563-565, 1998

23. Sundaram MB, Chow F: Seizures associated with spontaneous subarachnoid hemorrhage. Can J Neurol Sci 13:229231,1986

24. Teasdale G, Jennett B: Assessment of coma and impaired consciousness. A practical scale. Lancet 2:81-84, 1974

25. van den Berg R, Foumani M, Schröder RD, Peerdeman SM, Horn J, Bipat S, et al: Predictors of outcome in World Federation of Neurologic Surgeons grade V aneurysmal subarachnoid hemorrhage patients. Crit Care Med 39:2722-2727, 2011

\section{Author Contributions}

Conception and design: Fung, Beck. Acquisition of data: Fung, Balmer, Abu-Isa. Analysis and interpretation of data: Beck, Fung, Balmer, Murek, Z'Graggen, Abu-Isa. Drafting the article: Beck, Fung, Balmer, Z'Graggen, Ozdoba, Haenggi, Jakob, Raabe. Critically revising the article: all authors. Reviewed submitted version of manuscript: all authors. Approved the final version of the manuscript on behalf of all authors: Beck. Statistical analysis: Murek.

\section{Correspondence}

Jürgen Beck, Department of Neurosurgery, Bern University Hospital, 10 Freiburgstr., 3010 Bern, Switzerland. email: juergen. beck@insel.ch. 